\title{
KELAS KOMUNITAS MENUNJANG TERCIPTANYA KARAKTER KOMUNIKATIF PESERTA DIDIK HOMESCHOOLING PALEMBANG
}

\author{
${ }^{1}$ Rosda Fajri Kafarisa $\&{ }^{\mathbf{2}}$ Muhammad Kristiawan \\ ${ }^{1}$ Guru Homeschooling Primagama Kota Palembang \\ ${ }^{2}$ Universitas PGRI Palembang \\ e-mail: ${ }^{1}$ kafarisarosdafajri@yahoo.co.id ${ }^{2}$ muhammad.kristiawan@yahoo.co.id
}

\begin{abstract}
This paper aimed at investigating the communicative character of learners that could be seen in the pleasure of talking, socializing and cooperating with others in the community class conducted by Homeschooling Primagama Palembang every Saturday morning. This paper was qualitative descriptive. The data were obtained in the form of observation, interview and documentation results compiled from the location of observation. The results showed that the existence of a community class held every once a week, made students of Primagama Homeschooling could work together and mingle neglecting the age and education, and can socialize with the surrounding environment.
\end{abstract}

Keywords: Community Class; Communicative Character; Homeschooling

\section{PENDAHULUAN}

Pada dunia pendidikan sekarang telah banyak muncul lembaga pendidikan, dari pendidikan formal, pendidikan nonformal dan pendidikan informal. Yang tujuan setiap lembaga pendidikan sama yaitu mencerdaskan anak bangsa. Dalam implementasinya, ketiga lembaga pendidikan itu berkembang dengan keunikannya masing-masing. Di mana pendidikan formal telah menjadi keutamaan dan keharusan dalam penyelenggaran pendidikan. Begitu pula dengan pendidikan nonformal yang menjadi pelengkap pendidikan formal dalam menambah pengetahuan, keterampilan dan sikap peserta didik. Untuk pendidikan informal yang lebih dikenal dengan kegiatan belajar secara mandiri, belum sepenuhnya mendapat kepercayaan dari masyarakat.
Dalam pendidikan formal kerapkali hanya tertuju pada penilaian kognitif tanpa melihat segi afektif dan psikomotorik peserta didik, yang membuat peserta didik memandang belajar merupakan tekanan bukan sebagai kebutuhan. Dari itu munculah beberapa alternatif pendidikan salah satunya konsep Sekolah Mandiri yang merupakan program pendidikan informal. Sekolah Mandiri atau Sekolah Rumah atau lebih dikenal sebagai Homeschooling hadir untuk menumbuhkan keinginan belajar anak secara fleksibel dan membantu anak belajar dengan menyenangkan.

Serupa dengan Holt, Ray dan Dorothy Moore kemudian menjadi pendukung dan konsultan penting Homeschooling. Setelah itu, Homeschooling terus berkembang dengan berbagai alasan. Selain karena alasan keyakinan (beliefs), pertumbuhan 
Homeschooling juga banyak dipicu oleh ketidakpuasan atas sistem pendidikan di sekolah formal (Sumardiono: 2007).

Munculnya Homeschooling juga membawa banyak manfaat bagi kalangan artis, atlet, entertainer dan bahkan orang biasa pun yang sulit memperoleh pendidikan. Banyak juga alasan mengapa orang lebih memilih Homeschooling karna berbagai alasan, misalnya trauma dibullying, berpindah-pindah tempat bekerja orang tua, mogok sekolah, tingkat kecerdasan anak yang berbeda dan sebagainya. Karena itulah hadir Homeschooling untuk memberikan kenyamanan dalam proses kegiatan belajar mengajar.

Tetapi banyak mitos yang muncul dari ketidaktahuan tentang kegiatan Homeschooling sebenarnya. Banyak orang berasumsi bahwa dalam Homeschooling anak tidak punya teman, tidak belajar berkompetisi, pemalu dan tidak pernah keluar rumah sehingga menjadi kuper dan lain sebagainya. Hal itu dikarenakan bahwa anak Homeschooling tidak bersosialisasi dengan lingkungan sekitar. Padahal kenyataannya anak Homeschooling lebih banyak melakukan studi lapangan, yang memunculkan interaksi dengan orang lain tak hanya dengan teman sebaya tetapi seluruh lapisan usia dan pekerjaan.

Homeschooling adalah salah satu model pendidikan yang memperkaya model pendidikan di Indonesia. Ia juga sebagai lembaga pendidikan alternatif yang menunjang tujuan pendidikan Nasional di Indonesia. Dibawah payung hukum yang ada kehadirannya bukanlah sesuatu yang mesti diragukan. Peluang untuk tumbuh kembangnya di era globalisasi demikian membentang. Maka wajar bila keberadaannya mulai dilirik banyak kalangan. Inilah yang menjadi daya tarik untuk mengenalnya lebih dekat (Sugiarti: 2009)

Dari hasil rekap data yang dikumpulkan yang melibatkan 50 responden baik dari wawancara maupun pengisian instrumen kuisioner, dapat dilihat bahwa jalur pendidikan nonfomal dalam hal ini Homeschooling sudah diminati oleh masyarakat baik orang tua maupun anakanak. Selain itu diperoleh informasi, bahwa dalam pelaksanaan pembelajaran secara mandiri dari komunitas Homeschooling Griya Nusantara ini tidak lepas dari peran perangkat IT mulai dari hardware, software serta internet (Dyah: 2014).

Berdasarkan hasil penelitian diketahui bahwa pelaksanaan Homeschooling di Homeschooling Kak Seto Jakarta Selatan dapat dikatakan efektif sebagai pendidikan alternatif di dalam mengembangkan potensi anak dengan tercapainya aspek-aspek pembelajaran secara afektif dan optimal yang meliputi tiga tahap kegiatan yaitu tahap 
perencanaan, pelaksanaan dan penilaian. Dampak yang dihasilkan dari Homeschooling Kak Seto yakni dapat melanjutkan ke jenjang yang lebih tinggi, dapat belajar secara mandiri dan mampu membelajarkan orang lain serta berpatisipasi dalam kegiatan sosial. Agar dampak pelaksaan program Homeschooling ini dapat dirasakan efektivitasnya bagi peserta didik yang bermasalah maka pembiayaan pembelajaran di pendidikan Homeschooling diharapkan lebih terjangkau, tidak hanya untuk golongan keluarga menengah ke atas (Fitriana: 2016).

Dalam UU No. 20 tahun 2003 tentang Sistem Pendidikan Nasional pasal 27 menjelaskan 1) kegiatan pendidikan informal yang dilakukan oleh keluarga dan lingkungan berbentuk kegiatan belajar secara mandiri; 2) hasil pendidikan sebagaimana dimaksud pada ayat (1) diakui sama dengan pendidikan formal dan nonformal setelah peserta didik lulus ujian sesuai dengan standar nasional pendidikan. Sehingga keberadaan Homeschooling adalah legal dan peserta didik Homeschooling mendapat ijazah sebagaimana di pendidikan formal, sehingga dapat melanjutkan kejenjang pendidikan yang lebih tinggi.

Bukan hanya status sekolah yang telah mendapat izin dari Dinas Pendidikan, lebih dari itu Homeschooling lebih menekankan pada pemberdayaan potensi otak kiri dan otak kanan peserta didik. Melalui sistem pembelajaran yang dilakukan, yang terbagi menjadi kelas individu yang dimana peserta didik belajar secara mandiri di rumah, dimana saja dan kapan saja sesuai situasi dan kondisi yang nyaman dan menyenangkan bagi peserta didik. Dan kelas komunitas yang merupakan gabungan dari peserta didik Homeschooling yang tergabung dalam satu komunitas untuk belajar bersama dan lebih menekankan pada sifat dan sikap peserta didik untuk menjalin kerjasama, bergaul, kreatifitas, demokratis, religius, bersosialisasi dan peduli terhadap lingkungan sekitar.

Sikap dan tindakan pada kelas komunitas tersebut dapat menimbulkan dan menumbuh kembangkan 18 nilai pendidikan karakter bangsa yang diinginkan dan dibutuhkan oleh negara Indonesia. Kepmendiknas (2010) mengemukakan hasil diskusi dan sarasehan tentang "Pendidikan Budaya dan Karakter Bangsa" menghasilkan "Kesepakatan Nasional Pengembangan Pendidikan Budaya dan Karakter Bangsa" untuk berbagai wilayah Indonesia yang terdiri dari 18 nilai sebagai berikut: 1 . Religius, 2. Jujur, 3. Toleransi, 4. Disiplin, 5. Kerja keras, 6. Kreatif, 7. Mandiri, 8. Demokratis, 9. Rasa ingin tahu, 10. Semangat kebangsaan, 11. Cinta tanah air, 12. Menghargai prestasi, 13. Bersahabat/ komunikatif, 14. Cinta damai, 15. Gemar 
membaca, 16. Peduli lingkungan, 17. Peduli social, 18. Tanggung jawab.

Sunarti (2005) berpendapat bahwa karakter merupakan istilah yang menunjuk kepada aplikasi nilai-nilai kebaikan dalam bentuk tingkah laku. Walaupun istilah karakter dapat menunjuk kepada karakter baik atau karakter buruk, namun dalam aplikasinya orang dikatakan berkarakter jika mengaplikasikan nilai-nilai kebaikan dalam perilakunya. Oleh karena itu, maka permasalahan yang akan diungkapkan adalah bagaimana pendidikan karakter komunikatif dapat tercipta dikelas komunitas pada Homeschooling Primagama Palembang.

\section{METODE PENELITIAN}

Dalam melakukan pengamatan, peneliti menggunakan metode analisis deskriptif kualitatif. Dengan menggunakan metode analisis deskriptif kualitatif, peneliti berusaha mengambarkan suatu gejala sosial. Menurut Sugiyono (2005) menyatakan bahwa metode deskriptif adalah suatu metode yang digunakan untuk menggambarkan atau menganalisis suatu hasil penelitian tetapi tidak digunakan untuk membuat kesimpulan yang lebih luas.

Tujuan utama penelitian kualitatif adalah untuk memahami (to understand) fenomena atau gejala sosial dengan lebih menitik beratkan pada gambaran yang lengkap tentang fenomena yang dikaji daripada memerincinya menhadi variabelvariabel yang saling terkait. Pendekatan kualitatif merupakan descriptive; concerned with process rather than simply with outcomes or product; qualitative research tend the analyze their data inductively; and "meaning" is the essential concern to the qualitative approach (Kristiawan \& Tobari, 2017). Harapannya ialah diperoleh pemahaman yang mendalam tentang fenomena untuk selanjutnya dihasilkan sebuah teori. Karena tujuannya berbeda dengan penelitian kuantitatif, maka prosedur perolehan data dan jenis penelitian kualitatif juga berbeda (Rahardjo: 2010).

Data yang diperoleh pertama dari pengamatan, yang menurut Sugiyono (2013) menyatakan bahwa tekni pengamatan merupakan suatu proses yang kompleks, suatu proses yang tersusun dari berbagai proses biologis dan psikhologis. Yang semua itu berkaitan dengan makhluk hidup yang disini manusia yang berinteraksi dengan lingkungan sekitarnya. Pemakalah melakukan pengamatan langsung dengan mendatangi tempat penelitian di Homeschooling Primagama Palembang.

Kedua wawancara, menurut Esterberg dalam Sugiyono (2013) wawancara merupakan pertemuan dua orang untuk bertukar informasi dan ide melalui tanya jawab, sehingga dapat dikontruksikan 
makna dalam suatu topik tertentu. Teknik wawancara yang dilakukan pemakalah yaitu dengan mengajukan pertanyaan yang berkaitan tentang pendidikan Homeschooling dan pembelajarannya. Selain melalui pengamatan dan wawancara, pemajuga memperoleh informasi melalui dokumentasi berupa pengambilan gambar yang dilakukan pada saat berlangsungnya kelas komunitas di Homeschooling Primagama Palembang.

\section{HASIL PENELITIAN DAN PEMBAHASAN}

Dilihat dari tujuan pendidikan nasional yang tertuju pada pembentukan karakter bangsa, Kementerian Pendidikan Nasional mengembangkan kurikulum pendidikan karakter bangsa dengan berkembangnya 18 nilai karakter yang melalui tahapan pengetahuan menuju kebiasaan. Salah satu nilai karakter pendidikan yang dilihat adalah bersahabat/komunikatif yang diperlihatkan dengan senang bergaul, berbicara dan bekerja sama dengan orang lain, yang diimplementasikan pada kelas komunitas yang ada pada pendidikan informal yaitu Homeschooling Primagama Palembang.

Karakter pendidikan informal adalah bahwa pendidikan informal sama sekali tidak terorganisasikan secara struktural, tidak terdapat penjenjangan kronologis, tidak mengenal adanya kredensials, lebih merupakan hasil pengalaman belajar individu-mandiri dan pendidikanya tidak terjadi di dalam "medan interasi belajarmengajar buatan" sebagaimana pada pendidikan formal dan nonformal (Sutarto: 2007). Pendidikan informal sebagai wadah untuk menciptakan karakter bangsa adalah Homeschooling Primagama Palembang, "yang mulai operasional pada Januari 2012, dan merupakan Homeschooling yang pertama kalinya ada di Palembang bahkan untuk wilayah Sumsel sekitarnya," ujar Prof. Hazairin Samaulah, Direktur Homeschooling Primagama Palembang.

Pada Homeschooling Primagama Palembang membagi sistem belajar menjadi 2 bagian, yaitu Homeschooling individu dan Homeschooling komunitas dimana beberapa peserta didik HSPG bergabung dalam satu komunitas untuk belajar di Homeschooling Primagama yang sering disebut dengan kelas komunitas. Kelas komunitas merupakan kelas gabungan dari setiap jenjang peserta didik SD, SMP dan SMA, yang bertujuan agar peserta didik bisa bersosialisasi dan guru pun bisa melihat bakat dan minat dari setiap peserta didik melalui proses komunitas antar temannya.

Data yang diperoleh berupa hasil pengamatan, hasil wawancara dan hasil dokumentasi yang disusun dari lokasi pengamatan. Hasil wawancara yang dilakukan kepada direktur Homeschooling, kepala homechooling, pengajar, peserta 
didik dan staf kependidikan. Menyatakan kelas komunitas di adakan setiap sabtu pagi bertempat di halaman Homeschooling Primagama dan tempat-tempat lain yang telah disepakati. Berbagai macam kegiatan yang dilakukan dikelas komunitas dari pelajaran tambahan seperti agama islam, komputer, seni budaya, olahraga dan outing class. Dokumentasi yang diperoleh dari mulai tahun pelajaran 2017/2018 pada kelas komunitas antara lain Pembelajaran agama, seni budaya dan komputer peserta didik Homeschooling Primagama Palembang
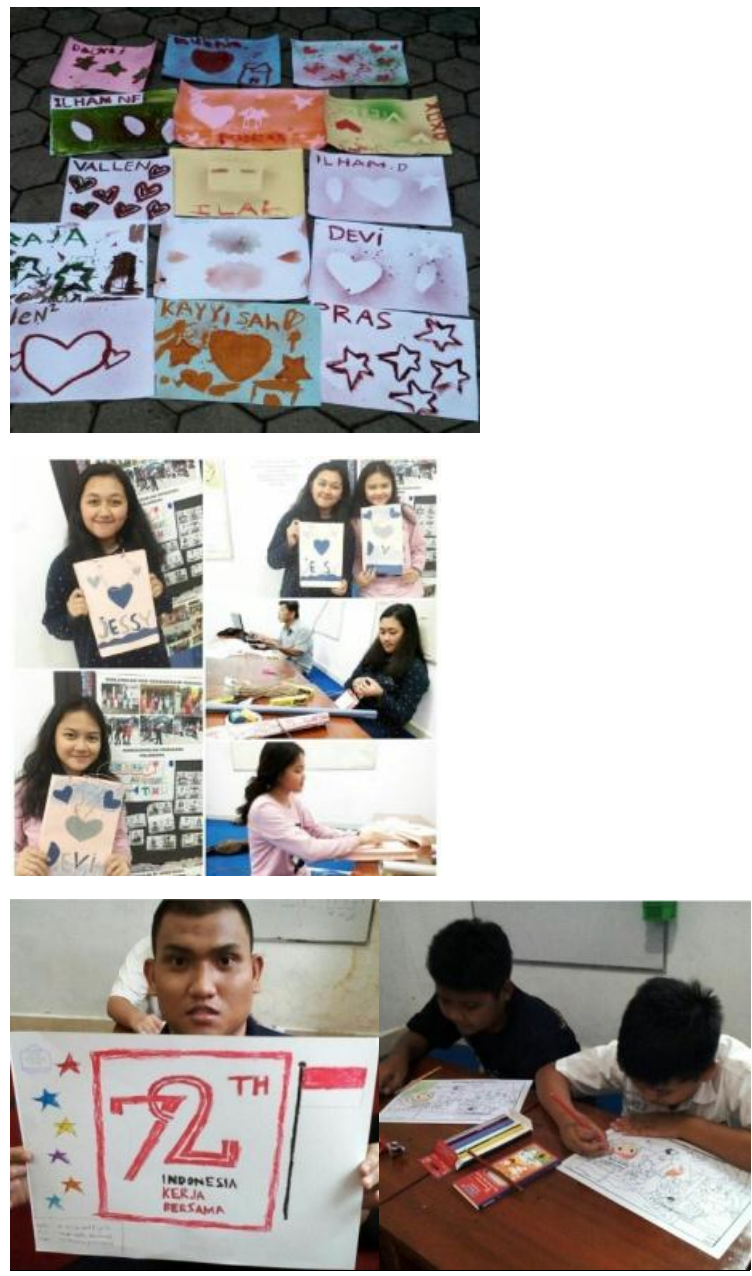


Olahraga sabtu pagi peserta didik Homeschooling Primagama Palembang
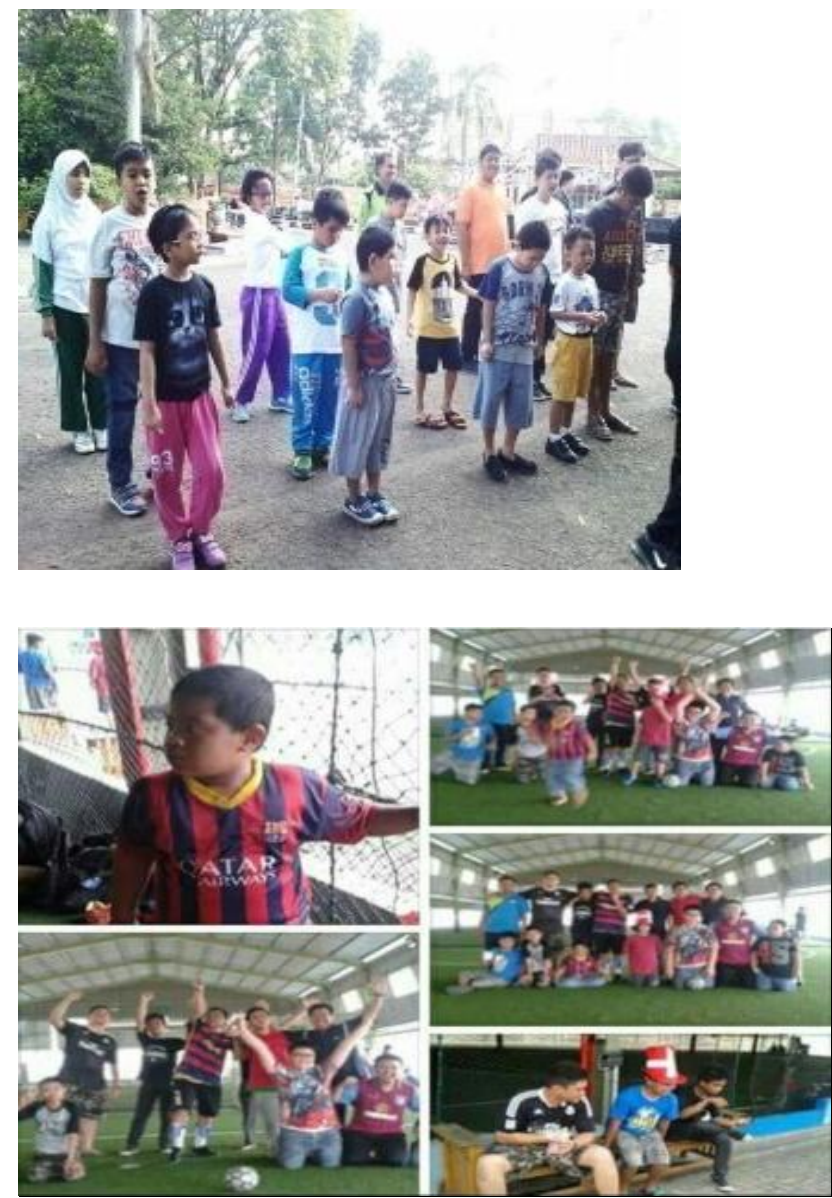

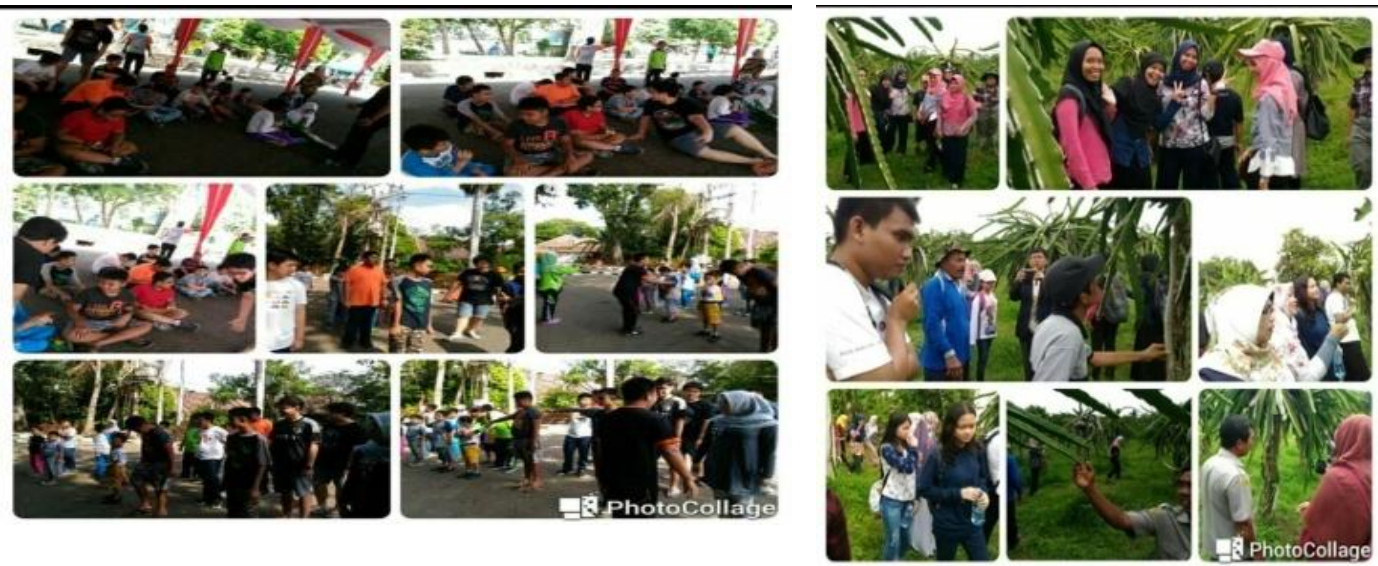

Cooking class peserta didik di hs dan di pizza hut

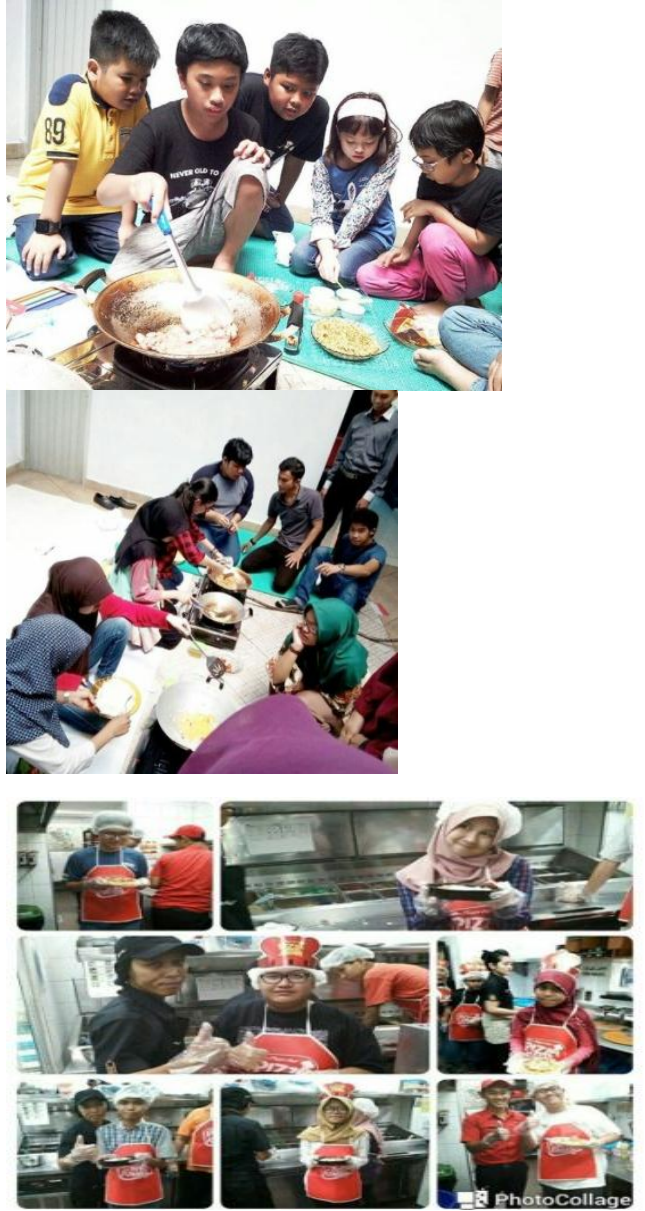

Kunjungan ke SMK Pertanian Sembawa


Kegiatan kelas komunitas selalu berlangsung dengan semangat peserta didik dan para pengajar Homeschooling Primagama Palembang. Tindakan yang terlihat jelas pada kelas komunitas adalah pendidikan karakter bersahabat atau komunikatif yang memperlihatkan senang berteman dengan siapa saja, menghargai 
hasil orang lain, bekerja sama serta adanya kepedulian sesama teman.

Andrianto (2011) menjelaskan "karakter meliput serangkaian sikap seperti keinginan untuk melakukan hal yang terbaik, kapasitas intelektual, seperti berpikir kritis dan alasan moral, perilaku seperti jujur dan bertanggung jawab, mempertahankan prinsip-prinsip moral dalam situasi penuh ketidakadilan, kecakapan interpersonal dan emosional yang memungkinkan seseorang berinteraksi secara efektif dalam berbagai keadaan, dan komitmen untuk berkontribusi dengan komunitas dan masyarakat".

Menurut Suprapto (Kristiawan: 2016) pendidikan karakter tidak sekedar mengajarkan mana yang benar dan mana yang salah, tetapi juga menanamkan kebiasaan (habituation) tentang hal mana yang baik. Dengan begitu, peserta didik menjadi paham (kognitif) tentang mana yang baik dan salah, mampu merasakan (afektif) nilai yang baik (loving the good/moral feeling), dan perilaku baik (moral action) dan biasa melakukan (psikomotor).

Sama halnya dengan nilai karakter bangsa yang tertera pada pusat kurikulum pendidikan nasional mengenai pendidikan karakter bersahabat atau komunikatif yang merupakan sikap dan tindakan yang mendorong dirinya untuk menghasilkan sesuatu yang berguna bagi masyarakat, mengakui dan menghormati keberhasilan orang lain serta tindakan yang memperlihatkan rasa senang berbicara, bergaul dan bekerja sama dengan orang lain (Kepennas: 2010).

Terlihat bahwa mitos yang berasumsi bahwa anak homemeschooling tidak bersosialisasi dengan lingkungannya tidak benar. Seperti ditanya imej Homeschooling yang terkesan rumahan, semua itu langsung ditepis oleh Prof. Hazairin Samaulah. "Walaupun sistem pendidikannya belajar dirumah, tetapi pergaulan anak-anak Homeschooling tidak perlu dikhawatirkan. Karena setiap satu minggu sekali pasti akan kumpul yang dikemas dengan sebuah komunitas peserta didik Homeschooling" ujar Hazairin.

\section{KESIMPULAN}

Homeschooling Primagama Palembang merupakan pendidikan informal sebagai lembaga pendidikan alternatif yang menunjang tujuan pendidikan Nasional di Indonesia. Homeschooling Primagama Palembang membagi sistem belajar menjadi 2 bagian, yaitu Homeschooling individu dan Homeschooling komunitas. Homeschooling komunitas atau biasa disebut kelas komunitas yang diadakan setiap sabtu pagi yang merupakan kumpulan peserta didik Homeschooling Primagama yang mengikuti pembelajaran tambahan baik teori maupun 
praktek. Adanya kelas komunitas yang diadakan setiap satu minggu sekali membuat peserta didik Homeschooling Primagama dapat bekerja sama dan bergaul tanpa adanya batasan baik usia maupun pendidikan, serta dapat bersosialisasi dengan lingkungan sekitarnya yang merupakan salah satu bentuk nilai pendidikan karakter bangsa yaitu senang bersahabat atau komunikatif.

\section{DAFTAR PUSTAKA}

Andrianto, Tuhana Tufiq. (2011). Mengembangkan Karakter Sukses Anak di Era Cyber. Yogyakarta: ArRuzz Media.

Dyah, H. (2014). Pengaruh Metode Homeschooling terhadap Minat Belajar Anak di Kecamatan Jaten Kabupaten Karanganyer. Jurnal Ilmiah go in fotech, vol. 20 No.1.

Fitriana, A. (2016). Efektivitas Pelaksanaan Pendidikan Homeschooling sebagai Pendidikan Alternatif dalam Mengembangkan Potensi Anak di Homeschooling kak Seto Jakarta Selatan. Jurnal Eksistensi Pendidikan Luar Sekolah(E-Plus), vol.1 No.1.

Kepennas. (2010). Pengembangan Pendidikan Budaya dan Karakter Bangsa. Jakarta: Badan Penelitian dan Pengembangan Kurikulum.

Kristiawan, M. (2016). Telaah Revolusi Mental Dan Pendidikan Karakter Dalam Pembentukkan Sumber Daya
Manusia Indonesia Yang Pandai dan Berakhlak Mulia. Ta'dib, 18(1), 13-25.

Kristiawan, M. (2017). The Characteristics of the Full Day School Based Elementary School. Transylvanian Review, 1(1).

Rahardjo, M. (2010). Jenis dan Metode Penelitian Kualitatif http://mudjiarahardjo.com/artikel/215. html?task=view.

Sugiarti, Diyah Y. (2009). Mengenal Homeschooling sebagai Lembaga Pendidikan Alternatif. Edukasi, vol. 1 No.2.

Sugiyono. (2005). Metode Penelitian Kuantitatif Kualitatif. Bandung: Alfabeta.

Sugiyono. (2013). Metode Penelitian Kuantitatif, Kualitatif dan $R \& D$. Bandung: Alfabeta.

Sumardiono. (2007). Homeschooling. Lambung cara belajar. Jakarta: PT Elek Media Komputindo.

Sunarti, E. (2005). Menggali Kekuatan Cerita. Jakarta: PT Elek Media Komputindo.

Sutarto, J. (2007). Pendidikan Nonformal. Semarang: UPT UNNES PRESS

Tim Pengembang. (2010). Desain Induk Pengembangan Karakter Bangsa Tahun 2010-2015. Jakarta: Kementerian Pendidikan Nasional.

Undang-Undang No. 20 Tahun 2003 tentang Sistem Pendidikan Nasional. 